\title{
Expression of PDL-1 and Its Correlation with TIL in Triple Negative Cases of Breast Carcinoma
}

\author{
Neha Sharma, Akashdeep Singh*, Arshdeep Kaur and Mridu Manjari \\ Department of Pathology, Sri Guru Ram Das Institute of Medical Sciences and Research Amritsar, Punjab. Pin-143001, India
}

\begin{abstract}
Background: In the present study, we aimed to determine the expression of PDL1 and its correlation with TIL in Triple Negative (ER, PR and Her 2neu negative) cases of breast carcinoma (immune-histochemical study)

Methods: Expression of PD-L1 was seen on 40 proven triple negative cases of breast carcinomas (TNBC) and to correlate it with other parameters affecting prognosis of the disease. All the cases were infiltrating ductal carcinoma NOS (not otherwise specified)

Result: Maximum cases were Grade III (67.5\%) followed by Grade II (32.5\%). PD-L1 positivity was seen in $32.5 \%$ cases whereas TIL was positive for PD-L1 in $27.5 \% .5$ cases were positive for both epithelial cell and TIL. Out of 13 PD-L1 positive tumors, $38.5 \%$ cases showed TIL positivity whereas out of 27 PD-L1 negative tumors, only $22.2 \%$ were TIL positive. PD-L1 expression in TIL was seen in $38.5 \%$ of cases however there was no statistically significant correlation between PD-L1 positivity and TIL positivity. PDL-1 positivity was more in Grade III (33.3\%) as compared to Grade II (23\%) lesions. Thus, it was observed that PD-L1 positivity increased from grade II to grade III lesions.

Conclusion: Intra-tumoral expression of PD-L1 is directly proportional to histological grade, aggressive subtypes in TNBC cases however there was no statistically significant correlation between PD-L1 positivity in tumor cells and TIL positivity. We thus postulate that measurement of PD-L1 expression in TNBC cases could enhance the accuracy of predicting patient prognosis and allow for optimal treatment selection.
\end{abstract}

Keywords: Programmed Death Ligand (PD-L1), Carcinoma, Breast, Immunohistochemistry

\section{Introduction}

Breast cancer is one of the most common cancers and also the primary cause of mortality due to cancer in females around the world and accounting for $22.9 \%$ of all cancers in women worldwide ${ }^{[1]}$. In Asia, one out of every 35 women suffers from breast cancer. However, there is a huge difference in breast cancer survival rates worldwide, with an estimated 5year survival of $80 \%$ in developed countries to below $40 \%$ for developing countries [2]. In India it constitutes $>30 \%$ of all cancers in females in urban areas and it is the second most common cancer next to carcinoma cervix, in terms of both incidence as well as mortality in rural areas ${ }^{[3,4]}$.

Although men have poorer outcome, breast carcinoma is 100 times more common in women ${ }^{[1]}$. The average age of developing carcinoma has changed drastically with younger women being affected in nearly half of the cases ${ }^{[5]}$. So, a palpable lump breast should be investigated as it turns out to be malignant in about $10 \%$ of the cases below the age of 40 years and this incidence increases to $60 \%$ in females older than 50years of age ${ }^{[6]}$.

Breast cancer can be detected most effectively with an accurate clinical history, clinical examination, radiological and pathological investigations ${ }^{[7]}$.
Immunohistochemical expression of tumor markers used in breast carcinoma are estrogen and progesterone receptors (ER/PR), Her-2neu, Ki67, p53, cyto-keratins, BRCA-1, BRCA-2, Androgen receptor (AR) and more recently Programmed death ligand (PD-L1), the indicators for prognosis and framing of treatment modalities ${ }^{[8]}$.

The Programmed Death Ligand (PD-L1), an immunoglobulin super family haplo-type 1 trans-membrane glycoprotein is associated with apoptosis and binds to PD-1 receptor ${ }^{[9]}$. PD1 (Programmed Cell Death receptor 1) is an immune checkpoint inhibitor which is expressed on the surface of immune effector cells such as surface of T-Cells, B cells, natural killer cells, monocytes and dendritic cells but not on resting T-cells. It was originally isolated from a $\mathrm{T}$-cell hybridoma undergoing T-cell receptor activation induced cell death, hence its name, Programmed Cell Death Receptor ${ }^{[10]}$. The expression of PD-L1 is regulated by both extrinsic and intrinsic mechanisms ${ }^{[11,12]}$. As a variety of mutations are seen in cancers, the biological signaling pathways may play a pivotal role in aberrant PD-L1 expression in cancer cells ${ }^{[13]}$.

\section{Materials and Methods}

The present study was conducted on 40 cases of ER, PR and Her2-neu negative cases of proven breast cancer received 
as mastectomy specimens in the Department of Pathology, Sri Guru Ram Das Institute of Medical Sciences, Sri Amritsar. The tissues were formalin fixed and paraffin embedded and then were stained with Haematoxylin and Eosin for histopathological typing and grading: The histopathological grading of the breast carcinoma was done according to the Nottingham modification of the Bloom Richardson grading system. Al the cases were subjected to immunohistochemistry for PD-L1 (Biocare Medical). Prior approval of institutional ethical committee was taken for the study.

Results and interpretation of the IHC scoring ${ }^{[9]}$

Positive and negative controls were run with every batch of the IHC. Positive control tissue showed colored end product at the site of target antigen. Negative control tissue section did not show the above color, implying that the tissue which was having colored end product had antibody specific antigen.

PD-L1 Presents a positive color of Yellow to Brown particles in the membrane/cytoplasm. Depending on the intensity of staining, score of 0-3(no color to dark brown) was given to the cells. The percentage of positive cells was given score from $1(<10 \%)$ to $3(>50 \%)$. Integrated score (Immunohistochemical scores, IHS) $=$ Staining intensity (a) X Score of percentage of positive cells (b) Positive result $=>3$ points.

\section{Statistical Analysis}

The software Statistical Package for the Social Sciences version 15.0 (SPSS Inc.; Chicago, IL, USA) was used for the statistical analysis. Comparisons of ratios in independent groups were performed with Chi-Square Analysis. P values lower than 0.05 were considered statistically significant.

\section{Result}

In our cohort, we have included 40 TNBC samples All the patients in the study were females. Age of the patients varied from 20 to 80 years. Most of the patients belonged to the age group of $40-60$ years $(57.5 \%)$ of the total. Right side was more commonly involved $(55 \%)$ of cases. All the 40 cases were infiltrating ductal carcinoma NOS (not otherwise specified). In maximum number of cases size varied from $2-3 \mathrm{~cm}$, comprising $40 \%$ with $20 \%$ being less than $2 \mathrm{~cm}$ in size. Maximum (67.5\%) cases were of Grade III, followed by Grade II which comprised 32.5\% of all the cases (Fig1-4). None of the case was of Grade I. Lymphovascular invasion (LVI) was seen in 33 cases $(85 \%)$ of the cases. Lymph nodes were recovered in 20 out the 40 cases of mastectomy specimen. Metastatic carcinomatous deposits were present in 20 cases with 7 cases $(17.5 \%)$ of N1 Stage (1-3 positive nodes), 04 cases (10\%) of N2 stage (4-9 positive nodes) and 09 cases $(22.5 \%)$ of N3 stage ( $>10$ positive nodes) with rest showing reactive hyperplasia.

PD-L1 expression in the tumour cells was positive in 13 cases $(32.5 \%)$ whereas 27 cases $(67.5 \%)$ were negative. At the same time tumor infiltrating lymphocytes (TIL) positivity was seen in $11(27.5 \%)$ cases (Table1).

Out of 13 PD-L1 positive tumors, 5(38.5\%) cases also showed TIL positivity whereas out of 27 PD-L1 negative tumors, only 6 cases $(22.2 \%)$ were TIL positive. PDL1 expression in TIL was seen in $38.5 \%$ of cases where expression was also seen in tumor cells, however there was no statistically significant correlation between PD-L1 positivity in tumor cells and TIL positivity as the $p$ value was 0.28 (Table 3).

PDL-1 positivity was more in Grade III as compared to Grade II lesions. Thus, it was observed that PD-L1 positivity increased from grade II to grade III so was directly proportional to grade. No definite correlation was seen with age, tumor size, lymphovascular invasion, lymph node involvement.

\section{Discussion}

The incidence of breast cancer in India is on the rise and is rapidly becoming the number one cancer in females pushing cervical cancer to second spot. Studies done

Table 1: correlation of PD-L1 with grade, lympho-vascular invasion and lymph node status.

\begin{tabular}{|c|c|c|c|c|c|c|c|c|}
\hline \multirow[t]{2}{*}{ PD-L1 } & \multicolumn{2}{|l|}{ Grade } & \multicolumn{2}{|c|}{$\begin{array}{l}\text { Lympho- vascular } \\
\text { invasion }\end{array}$} & \multicolumn{4}{|c|}{ Lymph-node status } \\
\hline & II & III & Positive & Negative & No & N1 & N2 & N3 \\
\hline Number of cases & 13 & 27 & 33 & 7 & 20 & 7 & 4 & 9 \\
\hline Positive & $\begin{array}{l}4 \\
(30.7 \%)\end{array}$ & $\begin{array}{l}9 \\
(33.3 \%)\end{array}$ & $\begin{array}{l}17 \\
(51.5 \%)\end{array}$ & $\begin{array}{l}3 \\
(42.9 \%)\end{array}$ & $\begin{array}{l}7 \\
(35 \%)\end{array}$ & 0 & $\begin{array}{l}1 \\
(25 \%)\end{array}$ & $\begin{array}{l}4 \\
(44.4 \%)\end{array}$ \\
\hline Negative & $\begin{array}{l}9 \\
(69.2 \%)\end{array}$ & $\begin{array}{l}18 \\
(66.7 \%)\end{array}$ & $\begin{array}{l}16 \\
(48.5 \%)\end{array}$ & $\begin{array}{l}4 \\
(57.1 \%)\end{array}$ & $\begin{array}{l}13 \\
(65 \%)\end{array}$ & $\begin{array}{l}7 \\
(100 \%)\end{array}$ & $\begin{array}{l}3 \\
(75 \%)\end{array}$ & \begin{tabular}{|l}
5 \\
$(55.6 \%)$
\end{tabular} \\
\hline
\end{tabular}


Table 2: correlation of TIL with grade, lympho-vascular invasion and lymph node status.

\begin{tabular}{|l|l|l|l|l|l|l|l|l|}
\hline TIL & \multicolumn{9}{l}{ Grade } & \multicolumn{2}{l|}{$\begin{array}{l}\text { Lympho-vascular } \\
\text { invasion }\end{array}$} & \multicolumn{2}{l|}{ Lymph-node status } \\
\hline & II & III & Positive & Negative & N0 & N1 & N2 & N3 \\
\hline Number of cases & 13 & 27 & 33 & 7 & 20 & 7 & 4 & 9 \\
\hline Positive & 6 & 7 & 8 & 4 & 9 & 3 & 1 & 8 \\
& $(46.2 \%)$ & $(25.9 \%)$ & $(24.2 \%)$ & $(57.1 \%)$ & $(45 \%)$ & $(42.9 \%)$ & $(25 \%)$ & $(88.9 \%)$ \\
\hline Negative & 7 & 20 & 25 & 3 & 11 & 4 & 3 & 1 \\
& $(53.8 \%)$ & $(74.1 \%)$ & $(75.8 \%)$ & $(42.9 \%)$ & $(55 \%)$ & $(57.1 \%)$ & $(75 \%)$ & $(11.1 \%)$ \\
\hline
\end{tabular}

Table 3: Correlation of PD-L1 expression with TIL.

\begin{tabular}{|l|l|l|}
\hline & PD-L1 POSITIVE CASES & PD-L1 NEGATIVE CASES \\
\hline TIL POSITIVE & $5(38.5 \%)$ & $6(22.2 . \%)$ \\
\hline TIL NEGATIVE & $8(61.5 \%)$ & $21(77.8 . \%)$ \\
\hline TOTAL & $\mathbf{1 3 ( 1 0 0 \% )}$ & $\mathbf{2 7 ( 6 7 . 5 \% )}$ \\
\hline
\end{tabular}

$p$ value $=0.28$ insignificant-chi square

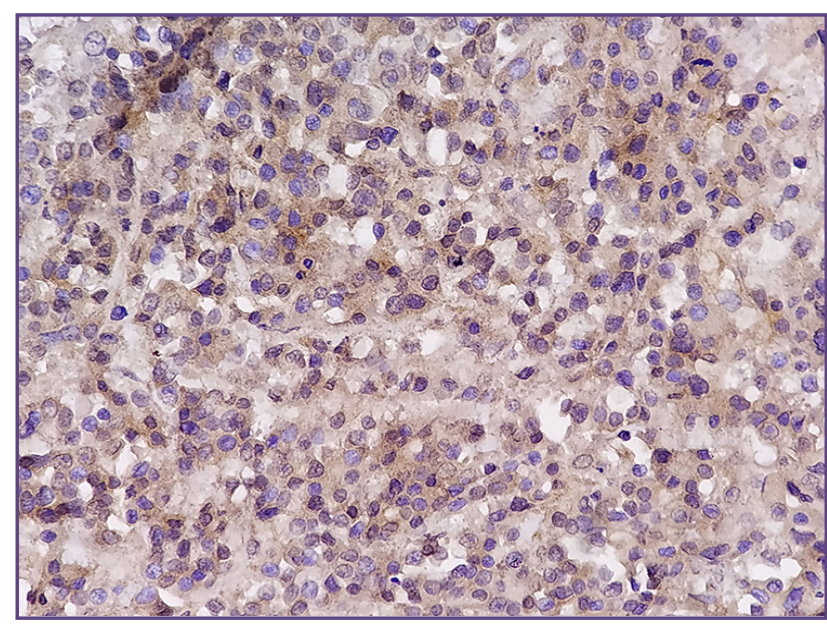

Fig. 1: IDC Grade III, PD-L1 positive- cytoplasmic, Magnification 40x, Stain- PDL1

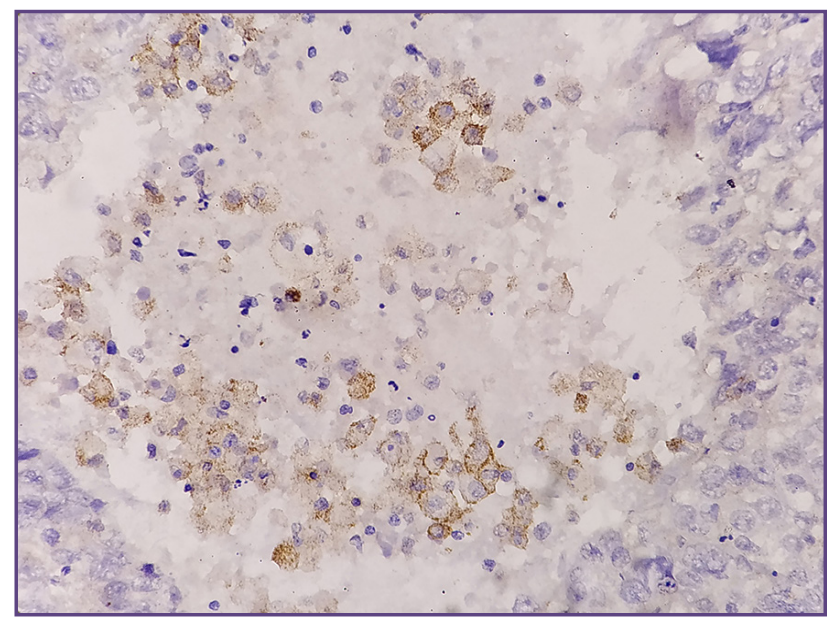

Fig. 3: IDC Grade II, PD-L1 positive- membranous, Magnification 40x, Stain- PDL1.

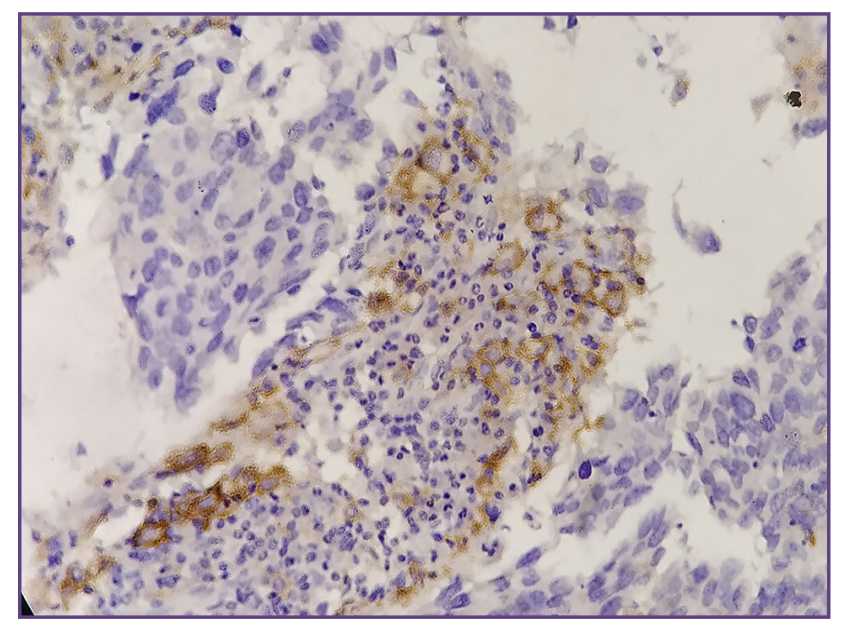

Fig. 2: IDC Grade II, TIL positive- membranous, Magnification 40x, Stain- PDL1.

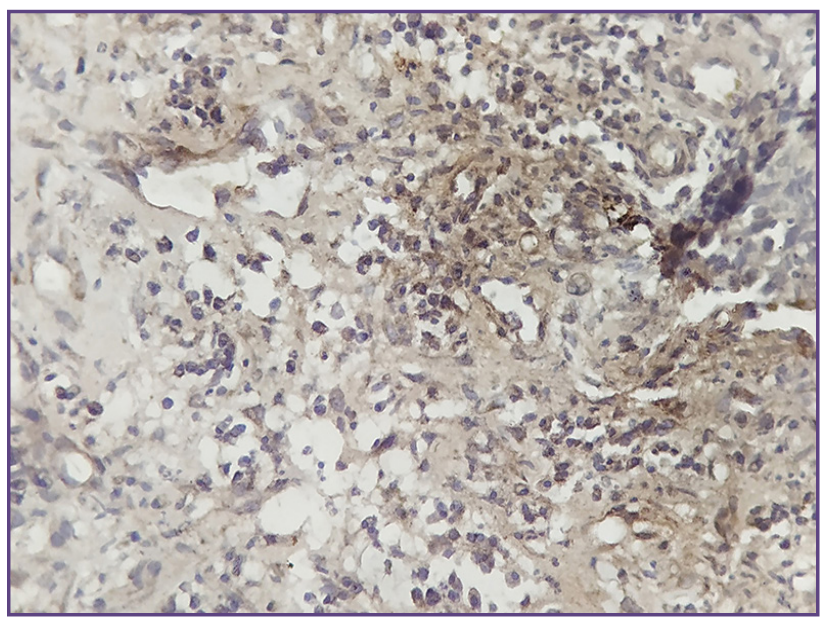

Fig. 4: IDC Grade II, TIL positive- cytoplasmic, Magnification 40x, Stain- PDL1. 
in different types of human cancers have confirmed the role of PDL-1 in the suppression of cellular immune responses. Various clinical and pathological variables such as age, size of tumor, histological grade, lymph node metastasis, vascular invasion, tumor necrosis and various immunohistochemical markers may help in predicting the prognosis and formulate the therapy

Age of the patients varied from 20 to 80 years. Most of the patients belonged to the age group of $40-60$ years $(57.5 \%)$ of the total. Right side was more commonly involved (55\%) of cases. Devesa and Hill in their studies on Carcinoma breast reported a mean age of 50 years in females ${ }^{[15,16]}$.

In the present study majority of the cases $(67.5 \%)$ cases were of Grade III, followed by Grade II which comprised $32.5 \%$ of all the cases. None of the case was of Grade I. Gouvea have reported $28.29 \%, 50.61 \%$ and $21.10 \%$ of Grade I, II, III cases respectively of invasive carcinoma [17]. Higher grade tumors have been reported in Indian studies as compared to the studies abroad, which may be due to the lack of awareness coupled with lack of routine mammographic screening.

Lymphovascular invasion (LVI) was seen in 33 cases ( $85 \%$ ) of the cases. Lymph nodes were recovered in 20 out the 40 cases of mastectomy specimen. Metastatic carcinomatous deposits were present in 20 cases with 7 cases $(17.5 \%)$ of N1 Stage (1-3 positive nodes), 04 cases (10\%) of N2 stage (4-9 positive nodes) and 09 cases $(22.5 \%)$ of N3 stage $(>10$ positive nodes) with rest showing reactive hyperplasia. Similar results have been reported by Rashmi et al with axillary lymph node involvement being $59.57 \%{ }^{[18]}$.

PD-L1 is a protein derived from CD274 gene. Its expression is regulated by both extrinsic and intrinsic mechanisms and is induced in numerous hematopoietic and non hematopoietic cells. In recent years, however the role of PD-L1 in tumor immunity has gained significant medical attention [19]. Studies done in different types of human cancers have confirmed the role of PDL-1 in the suppression of cellular immune responses. The intra tumoral expression of PDL1 is significantly associated with high histological grade, type of cancer being associated with more aggressive subtypes (basal and erb2 enriched), pathological type (more with ductal and medullary carcinoma) and TNM stage. It is highly associated with tumor size, Her-2neu status positivity, severe tumor lymphocyte infiltration and positive Ki67 status ${ }^{[9,14]}$.

Tumor Infiltrating Lymphocytes (TIL) in human cancers have been long thought to play a key role in inhibiting tumor proliferation, metastasis and may be an independent prognostic factor. The quantity of infiltrating lymphocytes within the tumor cells nests have been reported to correlate with an improved prognosis in many tumor types ${ }^{[20]}$.

As the PD-1 Signal stimulated the expression of proteins that decrease cytokine production and $\mathrm{T}$ cell proliferation thus either PDL-1 positivity in tumor cells or high level of PDL1 in TILs could be considered as potential responders to Anti PD1/PDL1 blocking agents as it decreases T cell survival and killing capacity ${ }^{[21-23]}$.

In the present study PD-L1 expression in the tumour cells was positive in 13 cases $(32.5 \%)$ and at the same time tumour infiltrating lymphocytes (TIL) positivity was also seen in $11(27.5 \%)$ cases similar results have been expressed by Lou J for PD-L1 expresssion being 37.75\% in breast carcinoma with Ghebeh $\mathrm{H}$ reporting it to be $34 \%$ and he also found that PD-L1 expression was not restricted to tumour epithelium only but was also expressed by TIL being $41 \%$ in his study

Out of 13 PD-L1 positive tumors, 5(38.5\%) cases also showed TIL positivity whereas out of 27 PD-L1 negative tumors, only 6 cases $(22.2 \%)$ were TIL positive. PDL1 expression in TIL was seen in $38.5 \%$ in cases where expression was also seen in tumor cells, however there was no statistically significant correlation between PD-L1 positivity in tumor and TIL positivity as the $p$ value was 0.28 . No definite correlation of PD-L1 positivity was seen with age. Sabatier R et al showed that PD-L1 positivity was significantly associated with size of tumour but no such correlation was seen in present study ${ }^{[14]}$. Lou J and Kurozumi $\mathrm{S}$ reported that PD-L1 expression in epithelial cells as well as TIL was significantly associated with pathological grade ${ }^{[9,24]}$ and it was also observed in the present study that expression of both is directly proportional to grade although it was not statistically significant probably because of less number of cases. No definite correlation was seen with LVI or LN status. Although AS Rathore showed that Intratumoral CD3+TIL are significantly associated with lymph node status (P value -0.06) [20] whereas Lou J found no definite correlation ${ }^{[9]}$.

\section{Conclusion}

Thus, it is concluded that intra-tumoral expression of PD-L1 is directly proportional to histological grade, aggressive subtypes, ER, PR and Her 2neu negative status however there was no statistically significant correlation between PD-L1 positivity in tumor cells and TIL positivity. Immunotherapy with anti-PD-L1 agents is emerging as a 
new treatment modality. Promising results have also been reported in advanced TNBC especially in metastatic setting whose tumors express PD-L1. We thus postulate that the measurement of PD-L1 expression in TNBC cases could increase the accuracy of predicting patient prognosis and better allow for optimal treatment selection.

\section{Acknowledgements}

This article and the research behind it would not have been possible without the exceptional support of my HOD madam Dr Mridu Manjari, my teachers, colleagues, lab staff at SGRD. The generosity and expertise of one and all have improved this study in innumerable ways and saved me from many errors; those that inevitably remain are entirely my own responsibility.

Finally, it is with true pleasure that I acknowledge the contributions of my amazing partner, Vikas Sharma who has given up many Sunday evenings to read every version of this article.

\section{Funding}

None

\section{Competing Interests}

None

\section{Reference}

1. Patil VW, Singhai R, Patil AV, Gaurav PD. Triple negative (ER, PR, Her2/neu) breast cancer in Indian women. Breast Cancer: Targets and Therapy. 2011;3(2):9ss-19.

2. Akram M, Iqbal M, Daniyal M, Khan AU. Awareness and current knowledge of breast cancer. Biol Res. 2017;2;50(1):33.

3. Khokhar K. Breast Cancer in India: Where do we stand and where do we go. Asian Pacific J Cancer Prev. 2012;13(10):4861-6.

4. Shetty P. India faces growing breast cancer epidemic. Lancet. 2012 Mar 17;379(9820):992-3.

5. Gupta S. Breast cancer: Indian experience, data and evidence. South Asian J Cancer. 2016 Sep;5(3):85-6.

6. Lester SC. The Breast. In: Kumar V, Abbas AK, Fausto N, Aster JC, editors. Robbins and Cotran Pathologic Basis of Disease. 8th ed. Philadelphia. Elsevier; 2010. p. 1066-90.

7. Allred DC. Ductal carcinoma in situ: terminology, classification and natural history. J Natl Cancer Inst Monogr. 2010 Nov;2010(41):134-8

8. Rosai J. The Breast. In: Mosby Elsevier. Rosai and Ackerman's Surgical Pathology. 10th ed (Vol.2). New York; 2005. 1763-1876

9. Lou J, ZhouY, Huang J, Qian X. Relationship between PDL1 expression and clinical characteristics in patients with breast invasive ductal carcinoma. Open Med (Wars). 2017; 12: 288-292.
10. Schutz F, Stefanovic S, Mayer L, Au AV, Domschke C, Sohn C. PD-1/PD-L1 pathway in breast cancer. Oncol Res Treat. 2017;40(5):294-297.

11. Sznol M, Chen L. Antogonist antibodies to PD-1 and B7-H (PD-L1) in the treatment of advanced human cancer. Clin Cancer Res. 2013 March;19(5):1021-34. PMID: 23460533 DOI: 10.1158/1078-0432.CCR-12-2063.

12. Kryczek I, Wei S, Gong W, Shu X, Szeliga W, Vatan L. Cutting edge: IFN-gamma enables APC to promote memory Th17 and abate Th1 cell development. J Immunol. 2008 Nov 1;181(9):5842-6.

13. Yang CY, Lin MW, Chang YL, Wu CT, Yang PC. Programmed cell death- ligand 1 expressiom in surgically resected stage 1 pulmonary adenocarcinoma and its correlation with driver mutations and clinical outcomes. Eur J Cancer. 2014 Feb;50(7):1361-9.

14. Sabatier R, Finetti P, Mamessier E, Adelaide J, Chaffanet M, Ali HR. Prognostic and predictive value of PDL1 expression in breast cancer. Oncotarget. 2015 Mar 10;6(7):5449-64.

15. Devesa SS, Blot WJ, Stone BJ, Miller BA, Tarone RE, Fraumeni JF. Recent cancer trends in United States. J Natl Cancer Inst. 1995 Feb;87(3):175-82.

16. Hill TD, Khamis HJ, Tyczynski JE, Berkel HJ. Comparison of male and female breast cancer incidence trends, tumor characteristics and survival. Ann Epidemiol [Internet]. 2005 Nov [cited 2019 Aug 2];15(10):773-80. Available from:http://www.annalsofepidemiology.org/ article/S10472797(05)00012-8/fulltext DOI:10.1016/ j.annepidem .2005 .01 .001

17. Gouvea AP, Milanezi F, Olson SJ, Leitao D, Schmitt FC, Gobbi H. Selecting antibodies to detect HER2 overexpression by immunohistochemistry in invasive mammary carcinomas. Appl Immunohistochem Mol Morphol. 2006 Mar;14(1):103-8.

18. K Rashmi, Sharma J, Minhas SS, Mardi K. Hormone receptor status of breast cancer in the himalayan region of northern India. Indian J Surg . 2011 Jan;73(1):9-12.

19. Chemnitz JM, Parry RV, Nichols KE, June CH, Riley JL. SHP-1 and SHP-2 associate with immunoreceptor Tyrosinebased switch motif of Programmed death 1 upon primary human $\mathrm{T}$ cell stimulation, but only receptor ligation prevents T cell activation. J Immunol. 2004 July;173(2): 945-54.

20. Rathore A S, Kumar S, Konwar R, Srivastava A N, Makker A, Goel M M. Presence of CD3+ tumour infiltrating lymphocytes is significantly associated with good prognosis in infiltrating ductal carcinoma of breast. Indian J Cancer. 2013 Sep;50:239-44.

21. Rosenberg JE, Censits JH, Powles Tom, Heijden MSV, Balar AV, Necchi A. Atezolizumab in patients with locally advanced and metastatic urothelial carcinoma who have progressed following treatment with platinum based chemotherapy. Lancet. 2016 May;387(10031):1909-20.

22. Herbst RS, Soria JC, Kowanetz M, Fine GD, Hamid O, Gordon MS. Predictive correlates of response to the anti- 
PD-L1 antibody. Nature .2014 Nov;515(7528): 563-7.

23. Baumeister SH, Freeman GJ, Dranoff G, Sharpe AH. Coinhibitory Pathways in Immunotherapy for Cancer. Annu Rev Immunol. 2016 May;34:539-73.
24. Kurozumi S, Matasumoto H, Kurosumi M, Inoue K, Fujii T, Horiguchi J. Prognostic significance of tumour infiltrating lymphocytes for oetrogen receptor negative breast cancer without lymph node metastasis. Oncol Lett. 2019 Mar;17(3):2647-56.

*Corresponding author:

Akashdeep Singh, Junior Resident, Department of Pathology, SGRDIMSR, Amritsar, Punjab. Pin-143001

Phone: +91 76962-33325

Email: akashdeepsingh769623@gmail.com

Date of Submission : 22/12/2020

Date of Final Revision : 02/05/2021

Financial or other Competing Interests: None.

Date of Acceptance : 05/06/2021

Date of Publication $\quad: 30 / 06 / 2021$ 